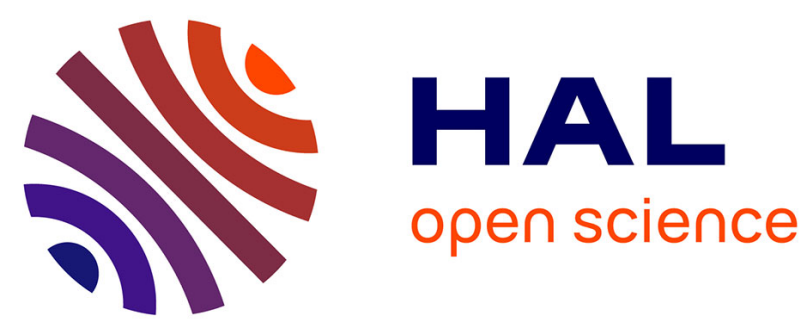

\title{
Effects of mechanical activation on chemical homogeneity and contamination level in dual-phase AlCoCrFeNi high entropy alloy
}

\author{
Adrien Fourmont, Sophie Le Gallet, Khalid Hoummada, Marion Descoins, \\ Clara Desgranges, Olivier Politano, Florence Baras
}

\section{To cite this version:}

Adrien Fourmont, Sophie Le Gallet, Khalid Hoummada, Marion Descoins, Clara Desgranges, et al.. Effects of mechanical activation on chemical homogeneity and contamination level in dualphase AlCoCrFeNi high entropy alloy. Materials Chemistry and Physics, 2021, 272, pp.125000. 10.1016/j.matchemphys.2021.125000 . hal-03347339

\section{HAL Id: hal-03347339 \\ https://hal.science/hal-03347339}

Submitted on 17 Sep 2021

HAL is a multi-disciplinary open access archive for the deposit and dissemination of scientific research documents, whether they are published or not. The documents may come from teaching and research institutions in France or abroad, or from public or private research centers.
L'archive ouverte pluridisciplinaire HAL, est destinée au dépôt et à la diffusion de documents scientifiques de niveau recherche, publiés ou non, émanant des établissements d'enseignement et de recherche français ou étrangers, des laboratoires publics ou privés. 


\section{Effects of mechanical activation on chemical homogeneity and}

\section{contamination level in dual-phase AICoCrFeNi High Entropy Alloy}

Adrien Fourmont ${ }^{1}$, Sophie Le Gallet ${ }^{1}$, Khalid Hoummada ${ }^{2}$, Marion Descoins ${ }^{2}$, Clara Desgranges ${ }^{3}$, Olivier Politano ${ }^{1}$, Florence Baras ${ }^{1}$

${ }^{1}$ ICB, UMR 6303 CNRS-Université Bourgogne Franche-Comté, 9 Av. Alain Savary, BP 47870, 21078, Dijon Cedex, France

${ }^{2}$ IM2NP, UMR 6242 CNRS-Aix Marseille Université, Case 142, Faculté de Saint Jérôme, 13397 Marseille Cedex 20, France

${ }^{3}$ Safran Tech, Materials and Processes Department, Rue des Jeunes Bois, Châteaufort, 78114, Magny-les-Hameaux, France

Corresponding author: Adrien Fourmont

E-mail address: adrien.fourmont@u-bourgogne.fr

AlCoCrFeNi High Entropy Alloys were here synthesized by the combination of Planetary Ball Milling and Spark Plasma Sintering at $1100{ }^{\circ} \mathrm{C}$. The relatively low rotating speed led to a peculiar agglomerate state referred to as "Mechanical Activated". The reactive sintering of activated agglomerates leads to a unique dual phase microstructure: the sintered sample exhibited a distinctive nanostructured lamellar microstructure consisting of two main phases (FCC and BCC). Atom Probe Tomography (APT) was used to ensure that the sintered sample was chemically homogeneous at the nanoscale in each phase. APT also revealed the presence of a Cr-rich sigma phase and oxide nanoprecipitates. X-ray Photoelectron Spectrometry (XPS) results demonstrated that most of the oxygen originated from the commercial powders. Calphad calculations revealed that the presence of oxides could alter the microstructure by modifying the global chemical composition. 


\section{Introduction}

High Entropy Alloys have attracted much attention since the pioneer articles by Yeh et al. [1] and Cantor et al. [2]. Materials scientists quickly realized the potential revolution inherent in the initial concept and generalized it to a broader topic: Complex Concentrated Alloys (CCA), alloys with no obvious base element [3].

One of the top five most studied compositions is $\mathrm{AlCoCrFeNi}$. Indeed, $\mathrm{Al}$ often represents the promise of light weight and high temperature oxidation resistance [4], two very important properties. However, for sintered and cast alloys, the $\mathrm{Al}_{\mathrm{x}} \mathrm{CoCrFeNi}$ composition is characterized by a large diversity of microstructures: these range from ordered Body Centered Cubic (BCC) precipitates (B2) in a disordered BCC matrix for $\mathrm{x}=1$ [5] to a single $\mathrm{BCC}$ or a single Face Centered Cubic (FCC) phase depending on the Al content [6,7]. In fact, the elaboration process plays an important role in microstructure formation. Indeed, the disordered $\mathrm{BCC}+\mathrm{B} 2$ microstructure is commonly observed in $\mathrm{AlCoCrFeNi}$ alloys prepared by arc-melting while other phases may appear as a result of powder metallurgy. Ji et al. observed the combination of B2 and disordered FCC phases [8] whereas other researchers reported much more complex microstructures containing disordered FCC, ordered FCC $\left(\mathrm{L1}_{2}\right)$ and tetragonal sigma phases [9-11].

One of the main challenges in HEA development is to understand the relation between the elaboration method and the resulting microstructure/properties. Only a small fraction of HEAs are synthesized by solid state processing, although HEAs elaborated this way often exhibit better homogeneity in their microstructures compared to those elaborated using the classical arc melting method [12]. Powder metallurgy has proven to be an alternative way to produce nanostructured HEA with promising properties [13-16]. However, most of the literature on powder metallurgy synthesis of HEAs reports the use of High Energy Ball Milling in order to reach complete Mechanical Alloying (MA). One of the main difficulties in this regard is the compromise between required time and milling power. This route often leads to contamination. Contamination during milling usually arises either via the Process Control Agent (PCA) [1720] which is used to prevent cold welding and oxidation, or by the grinding media such as WC 
or Fe [21,22]. Contamination does not necessarily lead to a weakening of desired properties. It remains of the highest importance to precisely control the amounts of minor elements $(\mathrm{C}, \mathrm{O}$ or $\mathrm{N})$ during the elaboration process.

Addressing this issue in their review, Vaidya et al. identified several challenges in the development of HEAs processed by powder metallurgy [23]. They highlighted the importance of producing a contamination-free alloy in order to thoroughly understand the key features of nanostructured HEAs, that is, without taking into account the role of minor elements. They also suggested that understanding the discrepancies between Calphad predictions and experimental results was one of the next steps in improving the production of HEAs by powder metallurgy. In fact, two main factors may induce such discrepancies: the out of equilibrium process associated with powder metallurgy and contamination by minor elements. A study evaluating the relative contribution of each factor would be truly valuable.

In the present work, Medium Energy Ball Milling was used in order to reach mechanical activation. The corresponding milling power and time alleviates the main drawbacks of solid state processing such as contamination by minor elements. The mechanical activation enhances particle reactivity by creating defects and by increasing the number of interfaces between reactants [24]. However, a solid solution is not formed during milling. This manner of elaborating alloys shifts the critical step to the sintering, which can be easier to handle. Preliminary studies on mechanical activation have confirmed the potential interest of this production method of High Entropy Alloys. A first reserve, however, is that one might expect to obtain a final inhomogeneous stage as a result, arguing that the sintering of inhomogeneous agglomerates will lead to poor chemical distribution in the sintered alloy. Colombini et al. tried to perform short mechanical activation of the AlCoCrFeNi composition [25]. As-sintered samples exhibited complex microstructures. Only an annealing of 50h led to the formation of a single FCC phase and even here some chemical segregation remained. Emphasizing that the presence of carbides in HEAs influences their plasticity, John et al. studied the elaboration of $\mathrm{Al}_{0.3} \mathrm{CoCrFeNi}$ by mechanical activation and SPS [26]. They reported the formation of a major FCC phase with carbides and alumina precipitates. They demonstrated that mechanical activation efficiently decreased the amount of carbides and claimed that carbon came mainly from the toluene, used as a PCA. They suggested that dry milling could be one of the ways to improve the process. Concerning the formation of oxides during powder metallurgy processes, Kang et al. argued that most oxygen contamination occurred during the milling. They determined a minimum milling time limiting the contamination of the $\mathrm{Al}_{0.1} \mathrm{CrNbVMo}$ 
composition [27]. The sintered sample exhibited a major BCC phase with some alumina inclusions. They reported outstanding mechanical properties, such as high yield strength, as compared to as-cast similar refractory alloys.

In our previous work, we studied the influence of planetary ball milling on the synthesis of $\mathrm{AlCoCrFeNi}$ [28]. We demonstrated that long mechanical alloying was not mandatory in the elaboration of sintered alloys with high entropy solid solutions. In the present work, we used APT in order to provide valuable information on the distribution of all alloying elements, their spatial correlation and the nature of the nano-impurities which are not discernible or identifiable by more classical methods of characterization. New Calphad calculations were performed in order to take into account the nature of the precipitates in the global composition. These calculations shed light on the various factors that induce discrepancies between thermodynamic and experimental results.

\section{Method}

Elemental powders of $\mathrm{Al}, \mathrm{Co}, \mathrm{Cr}, \mathrm{Fe}$ and $\mathrm{Ni}$ of high purity (all $>99.2 \mathrm{wt} \%$, Alfa Aesar) were first blended with a TURBULA ${ }^{\circledR}$ mixer (WAB Turbula T2F) for 24 hours.

The blended powders were then processed by planetary ball milling (Fritsch Pulverisette 4) for $28 \mathrm{~h}$ with $2 \mathrm{~h}$ pauses every $7 \mathrm{~h}$. Pauses prevent the powder from adhering to the vial wall. The ratio between the weight of the balls and the powders was set at 7:1. The milling speed was set to $250 \mathrm{rpm}$ for the disk and the relative speed of the vials was $250 \mathrm{rpm}$. No process control agent was used to prevent any supplementary contamination.

The powders were subsequently consolidated by means of Spark Plasma Sintering (SPS, FCT Systeme $\mathrm{GmbH} \mathrm{HPD} 10$ ) at $80 \mathrm{MPa}$ in a $10 \mathrm{~mm}$ inner-diameter graphite die. A target temperature of $1100^{\circ} \mathrm{C}$ and a heating rate of $50^{\circ} \mathrm{C} / \mathrm{min}$ were used. No dwell time was applied in order to preserve the nanostructure of the material. Sintering was carried out in a vacuum. Grinding bowls and SPS dies were filled under argon atmosphere in order to avoid possible oxygen contamination.

The powders and the sintered samples (upper surfaces after polishing) were analyzed using XRay Diffraction with $\mathrm{Cu} \mathrm{K} \alpha$ radiation (XRD, Siemens D5000), scanning electron microscopy (SEM, JEOL JSM 7600F). Oxygen and Nitrogen were determined by the inert gas fusion method using LECO TC-136 and LECO TC-436AR oxygen/nitrogen analyzer. The carbon 
content was determined by LECO CS-744 carbon sulfur analyzer. Both kinds of chemical analyses were performed on powders and sintered samples.

X-ray Photoelectron Spectrometry (XPS) analyses were performed using a PHI 5000 Versaprobe apparatus with monochromatic Al Ka1 X-Ray source.

In addition, Atom Probe Tomography (APT) was performed on sintered samples. APT specimens were prepared via the lift-out technique using a dual-beam FIB-SEM [29]. The micro-tips were prepared by means of the annular milling method to obtain an end radius of $\sim 100 \mathrm{~nm}$. The APT analyses were carried out in a LEAP 3000X-HR instrument using the electrical pulsing mode $(100 \mathrm{kHz})$. The detection rate was kept at 0.002 event/pulse by progressively increasing the applied voltage. The specimen temperature and the fraction of pulsing were set to $80 \mathrm{~K}$ and $20 \%$ of applied voltage respectively.

\section{Results and discussion}

As we reported in a previous study, the milling parameters used in this work do not achieve complete Mechanical Alloying. The peculiar state of the milled powders is the specificity of the mechanical activation process. Comprehensive characterization of the powder is reported elsewhere [28].

\subsection{Mechanical activation of Al-Co-Cr-Fe-Ni powders}

Figure 1a depicts the diffractograms of the powder before and after milling. The FCC Al and HCP Co peaks completely disappear. Two sets of peaks remain observable: one corresponding to a Body Centered Cubic structure, lattice parameter: $2.87 \AA$ and the other corresponding to a Face Centered Cubic structure, lattice parameter: $3.53 \AA$ A. Contrary to results from more energetic milling of Al-Co-Cr-Fe-Ni powders [8], asymmetric FCC peaks are still observed after $28 \mathrm{~h}$ of milling in our case. The dissymmetry indicates that there is a gradient of concentration of other elements (especially Al which has a larger metallic radius than the others) in the FCC Ni-based matrix. Simply put, we can infer from the XRD that two intermediate solid solutions are formed but that complete Mechanical Alloying is not attained. Figure $1 \mathrm{~b}$ shows the SEM image of the cross section of the milled powder. The agglomerates are in an intermediate state between composite and Mechanically Alloyed. Indeed, the 
lamellae are very thin $(\sim 100 \mathrm{~nm})$ and are not perfectly pure, judging from the asymmetric peaks of the XRD.

Because of this peculiar starting state of the agglomerates, the sintering step is described as "reactive sintering”. Homogeneous high entropy solid solutions will actually be formed during sintering.
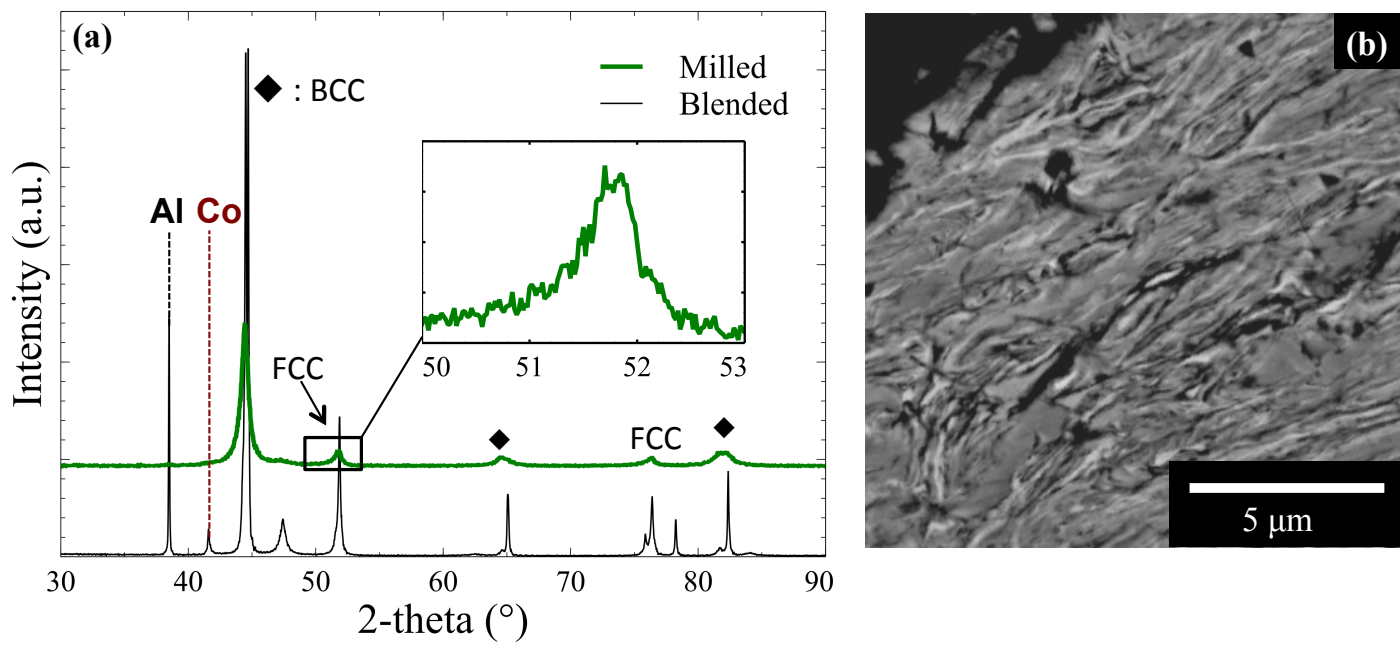

Figure 1 : (a) Diffractograms of blended and milled AlCoCrFeNi powders. The inset is a close-up view of the asymmetric (200) FCC peak. (b) BSE SEM cross-section of AICoCrFeNi milled agglomerates.

Figure 2a reveals the presence of three or four phases after sintering. The peak at $32^{\circ} 2 \theta$ indicates the formation of an ordered B2 phase. At this point, we do not know if the entire BCC phase is partly or fully ordered. There are very slight traces of a sigma phase $(2 \theta=$ $42.4^{\circ}$ ), a finding previously observed in other studies concerning HEA composition with $\mathrm{Cr}$ [30]. The lattice parameter of the FCC phase after sintering is $3.60 \AA$ and the peaks are no longer asymmetric. This observation suggests that there are two actual high entropy solid solutions, one FCC and one BCC (disordered and/or B2). Rietveld analysis indicates that the average crystallite size is approximately $100 \mathrm{~nm}$ for the two main phases and is not measurable for the sigma phase.

Figure $2 \mathrm{~b}$ depicts the unique microstructure obtained by reactive sintering. Indeed, after Mechanical Alloying followed by SPS densification, the microstructure is usually uniform [10]. Here, the microstructure is lamellar and very thin. The average width of a region is approximately $500 \mathrm{~nm}$. Two main contrasts are observed. EDX, EBSD and XRD analyses reveal that the bright one corresponds to a $\mathrm{Fe}-\mathrm{Cr}-\mathrm{Co}$ rich $\mathrm{FCC}$ phase and the dark one corresponds to an Al-Ni rich BCC phase. The volume ratio is estimated through our different 
characterization techniques to be around 50-50\%. The compositions of these phases, obtained by averaging ten points, are listed in table 1 . The sigma $(\sigma)$ phase, in addition to being in trace form as mentioned above, seems to have a very close BSE contrast to that of the BCC phase. We therefore did not manage to precisely evaluate the composition of sigma by means of EDX. The presence of black precipitates is also noticeable. It is not possible to precisely identify them by means of SEM EDX since their size never exceeds $10 \mathrm{~nm}$. They could be principally carbides (as commonly seen in Spark Plasma Sintered samples [31]) or oxides originating elsewhere [17]. EDX mapping was used but was not wholly conclusive on this point.

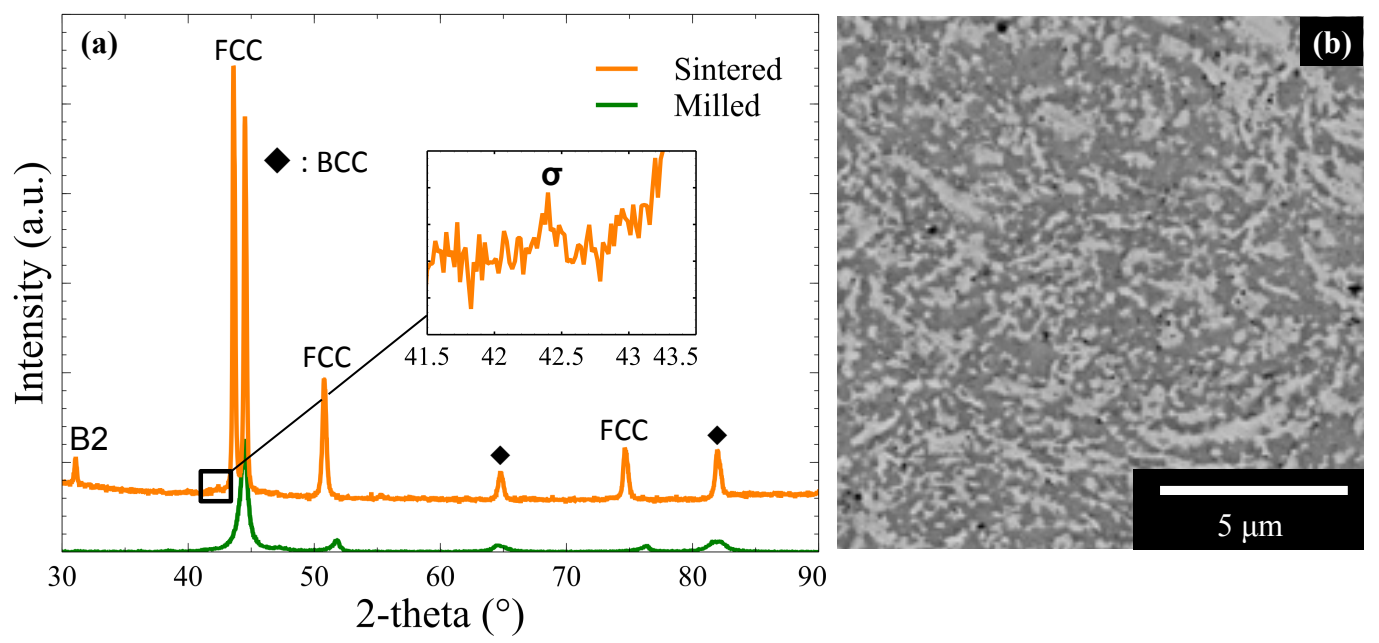

Figure 2: (a) Diffractograms of milled and sintered AlCoCrFeNi. The inset is a close-up view of the (112) $\sigma$ peak. (b) BSE SEM picture of AICoCrFeNi sintered alloy.

It should be noted that an EDX point radius is larger than the characteristic width of a lamella. At this point, we can observe the trend, but each point measures a small portion of the other phase as well.

Table 1: Average composition (at. \%) of main phases measured by SEM EDX.

\begin{tabular}{|c|c|c|c|c|c|}
\hline Phase & Al & Co & Cr & Fe & Ni \\
\hline \multirow{2}{*}{ FCC } & 8 & 25 & 26 & 26 & 16 \\
& \pm 1 & \pm 4 & \pm 2 & \pm 2 & \pm 2 \\
\hline \multirow{2}{*}{ BCC } & 27 & 17 & 16 & 15 & 24 \\
& \pm 1 & \pm 1 & \pm 3 & \pm 2 & \pm 3 \\
\hline
\end{tabular}




\subsection{Atom Probe Tomography investigation}

In order to more accurately address this question and shed some light on the microstructure at the atomic scale, Atom Probe Tomography was carried out.

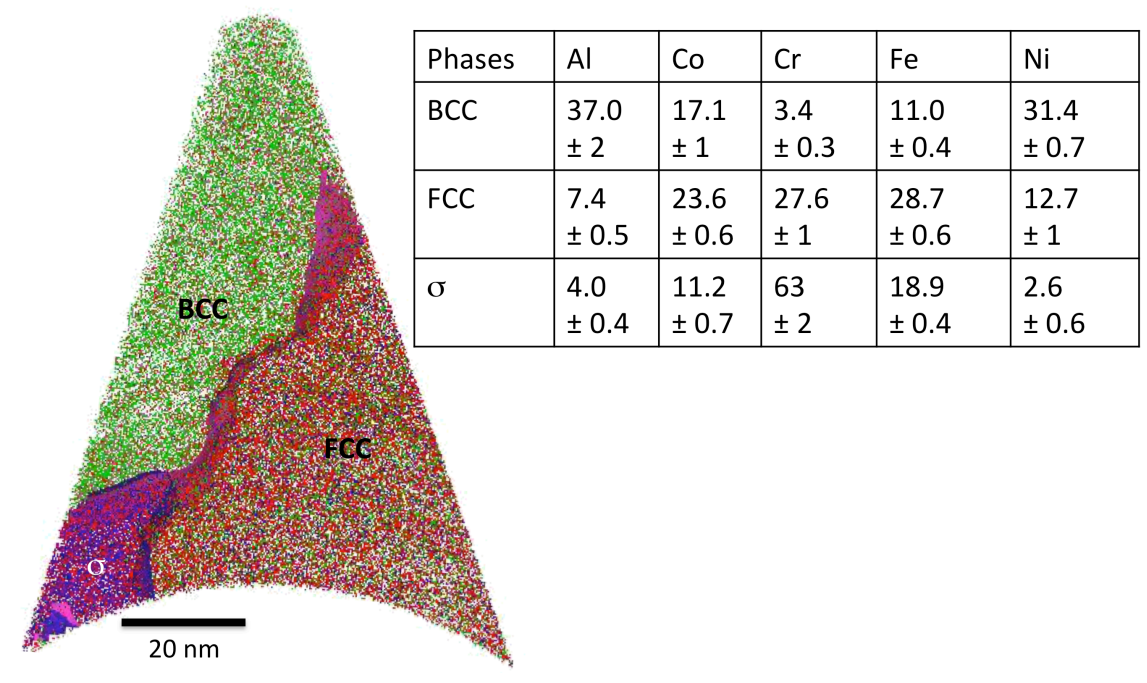

Figure 3 : APT reconstruction of the sintered AlCoCrFeNi alloy. Measured compositions (at. \%) of each phase with the standard deviations calculated from 3 volumes observed by means of APT. Three contrasts are observed in the chemical distribution.

Figure 3 shows the 3D reconstruction of one of the three analyzed volumes $(70 \mathrm{~nm} * 68 \mathrm{~nm} *$ $91 \mathrm{~nm})$. The total chemical composition of this volume is very close to equimolar. Two isoconcentration surfaces of 12 at. $\% \mathrm{Al}$ and 40 at. $\% \mathrm{Cr}$ reveal the interfaces between the three phases. Their compositions are summarized alongside the standard deviations in Fig. 3. The precise composition of the FCC phase is close to that measured using SEM EDX, whereas the precise composition of the BCC phase is very different. For example, the Aluminum content is measured at up to 37 at. \% instead of 27.5 at. \% as measured by means of SEM. The main reason for this discrepancy seems to be the Al-Ni rich $\mathrm{BCC}$ and the $\mathrm{Cr}$ rich sigma phases sharing the same BSE contrast, leading to an EDX composition averaged over the two phases. In addition, the standard deviations calculated from the composition of each phase from the three analyzed volumes indicate that each phase is very homogeneous from one region to another. The volume ratio between (sigma+BCC)/FCC in this volume is close to $50-50 \%$, corresponding to what has been observed at the microscopic scale. 
A proximity histogram calculated from the $\mathrm{BCC} / \mathrm{FCC}$ interface of Fig. 3 is shown in Fig. $4 \mathrm{a}$. There is almost no sign of segregation at the interfaces between the different phases, even though the starting agglomerates are not fully alloyed. Indeed, Figure 1 indicated that the milled powder was far from chemically homogeneous. We could reasonably have expected that this lack of homogeneity would impact the final sintered sample, but this is not the case. These phases are very homogenous and there is no strong fluctuation of $\mathrm{Fe}$ or $\mathrm{Cr}$, contrary to what was observed by Manzoni et al. by means of APT for the same as-cast alloy composition [32].

The sigma/BCC and sigma/FCC interfaces are tortuous; hence it is not possible to calculate proper proxigrams. A simple profile concentration through the sigma/BCC interface of the volume presented is depicted in Fig. 4b. This concentration profile reveals one of the very few examples of elemental segregation; in this case, the Fe surplus is higher at the interface (up to 12 at. \%). This segregation may be linked to the ongoing formation/dissolution of the sigma phase.
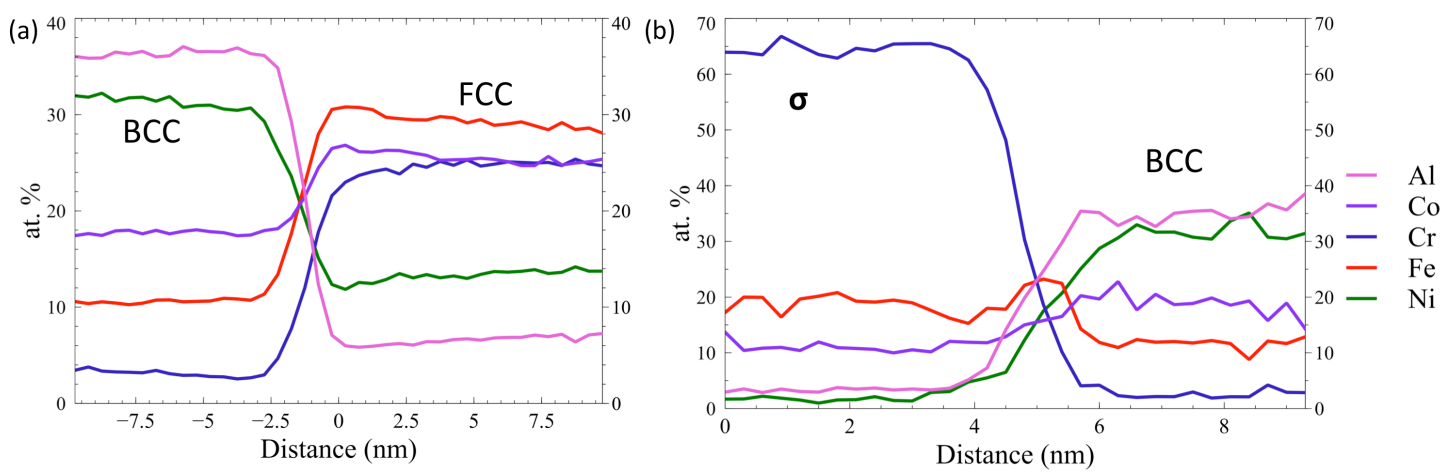

(c)

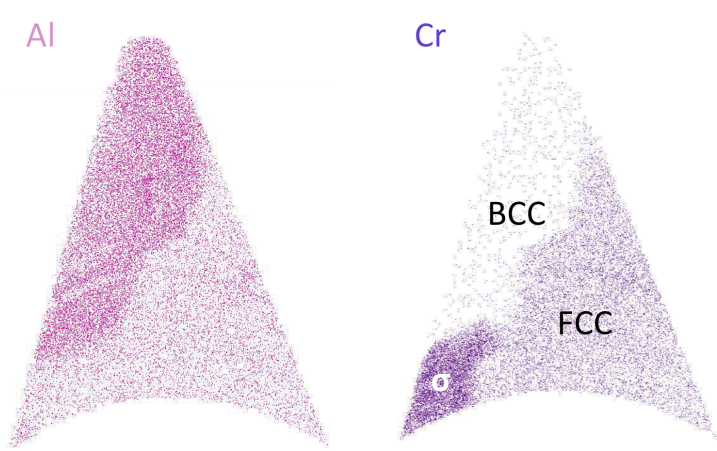

Figure 4: (a) Proximity histogram calculated from the BCC/FCC interface of the sintered AlCoCrFeNi alloy. (b) Concentration profile through one sigma/BCC interface in the sintered AlCoCrFeNi alloy. (c) Elemental mapping of the sintered AlCoCrFeNi alloy obtained by means of APT. 
Figure $4 \mathrm{c}$ shows the elemental mapping of the volume, confirming the presence of a homogenous Al-Ni rich phase, a Fe-Cr-Co phase and a $\mathrm{Cr}$ rich phase. There are several oxygen rich clusters. Hence, the black precipitates seen in the SEM can be identified thanks to the APT. They turn out to be oxides. No traces of carbides were observed, in contrast to what Pohan et al. [33] reported in their analysis of $\mathrm{Al}_{0.3} \mathrm{CoCrFeNiMn}$ by means of APT. The content of $\mathrm{C}$ measured by APT was less than 0.01 at. \% and carbon atoms seem to be in solid solution. $\mathrm{Al}_{2} \mathrm{O}_{3}$ and $\mathrm{Cr}_{2} \mathrm{O}_{3}$ are located at the interfaces of the three phases but not only. At this point, it is difficult to surmise their origin. All synthesis steps were carried out under controlled atmosphere, yet, according to the APT, the amount of oxygen is estimated at 0.5 at. $\%$.

\subsection{Oxygen contamination}

Oxygen contamination may arise at three stages [34]:

- in the commercial powders themselves;

- during milling (especially since our milling takes $28 \mathrm{~h}$ );

- during sintering due to the high reactivity of the mechanically activated agglomerate surfaces since the agglomerates have not reached the stable alloyed state.

In order to study the contamination by Oxygen during the process, precise O quantifications were carried out using the Inert Gas Fusion Technique at different stages (Table 2).

Table 2: Oxygen concentrations and standard deviations calculated from 4 measurements of the different samples measured by the Inert Gas Fusion Technique.

\begin{tabular}{|l|l|l|l|}
\hline & $\begin{array}{l}\text { Blended } \\
\text { Powder }\end{array}$ & $\begin{array}{l}\text { Milled } \\
\text { Powder }\end{array}$ & $\begin{array}{l}\text { Sintered } \\
\text { sample }\end{array}$ \\
\hline (wt. \%) & $0.6 \pm 0.1$ & $0.6 \pm 0.4$ & $0.5 \pm 0.4$ \\
\hline
\end{tabular}

The oxygen content in the initial blended powder is already quite high as compared to industrial alloys. Here, the oxygen comes from thin passivated layers in the case of $\mathrm{Al}$ and $\mathrm{Cr}$ $[35,36]$ and from less stable layers in the case of $\mathrm{Co}, \mathrm{Ni}$ and $\mathrm{Fe}[37,38]$. The standard deviation indicates that there may remain some regions richer in certain elements and particularly O-rich, despite the fact that the powders were blended for $2 \mathrm{~h}$. By comparison, the oxygen content in the milled powder does not increase, but the standard deviation is very 
high, nearly attaining the actual average value. It seems unlikely that the actual value would be lower than the initial concentration for blended powder. Hence, the real value should be close to $0.6 \%$. The standard deviation does thus not reflect a measurement error but rather an increased heterogeneity in oxygen distribution. The milling seems to induce a redistribution of oxygen atoms inside the agglomerates. It appears that the sintering stage does not alter this heterogeneity. At this point, these results suggest that most of the contamination originates in the initial powders and that the sintering step does not play a role in the oxygen contamination process.

In order to further investigate oxygen contamination, XPS analyses were carried out on powders originating from batches similar to the batches used for the oxygen quantification (Fig. 5). The XPS data analysis is challenging, due to the interference of the Auger transitions which overlap with $2 p$ peaks of the main elements in the alloy [39]. Despite this issue, the spectra quantification shows that the AlCoCrFeNi milled powder surface exhibits mainly $\mathrm{Al}_{2} \mathrm{O}_{3}$. Figure 5 in fact displays the A12p XPS window for a commercial Al powder and the AlCoCrFeNi milled powder. For this XPS measurement, the AlCoCrFeNi milled powder was handled in a protective atmosphere until the very moment of measurement. Consequently, the amount of powder measured is smaller than in the previous analysis and the spectrum exhibits more noise.

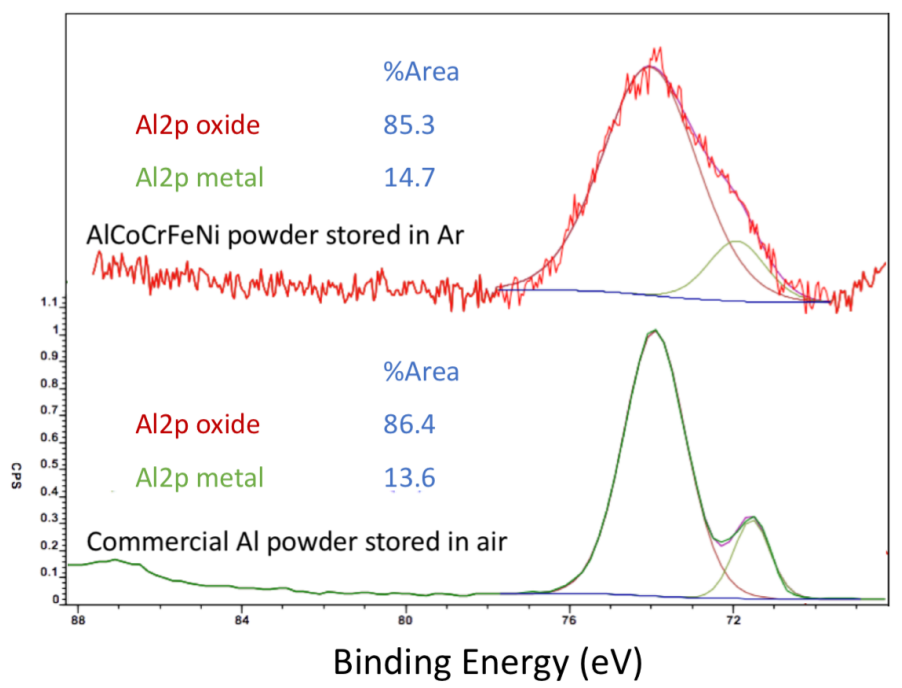

Figure 5 : XPS spectra of the Al2p window and corresponding quantification for the HEA powder stored in Ar (top) and commercial Al powder stored in air (bottom).

The commercial Al powder analyzed (bottom) corresponds to the one used in this work. The Al powder was stored for at least 30 days in air before analysis. We are confident that the 
storage of such powder is of minor importance for characterization purposes, since pure $\mathrm{Al}$ is highly reactive and rapidly forms a stable passivation layer (this layer is formed as soon as the powder is manufactured [40]). The finding shows that there is indeed a stable layer of oxide which does not exceed the $5 \mathrm{~nm}$ depth typical of XPS analysis. The spectrum of the AlCoCrFeNi milled powder, used for the sintered sample analyzed by APT, is displayed in Fig. 5, top. The spectrum reveals that the surface is mainly $\mathrm{Al}_{2} \mathrm{O}_{3}$ but that $14.7 \%$ of the aluminum is still metallic. This spectrum is very similar to that of pure $\mathrm{Al}$ and would indicate that a thin $\mathrm{Al}_{2} \mathrm{O}_{3}$ passivated layer is also formed in the case of milled $\mathrm{AlCoCrFeNi}$. The oxygen content corresponding to the presence of this thin oxide layer is significantly lower than the global oxygen level measured by the inert gas fusion technique. We can therefore conclude that most of the oxygen is inside the agglomerates, far from the surface measured by XPS.

APT analyses show that only $\mathrm{Al}_{2} \mathrm{O}_{3}$ and $\mathrm{Cr}_{2} \mathrm{O}_{3}$ are present in the sintered HEA. Yet, initially, the powders which contain the most oxygen are those of iron, nickel and cobalt. In addition, the oxygen content measured in the sintered HEA cannot result solely from the passivating layers of chromium and aluminum at the surface. We may thus infer that the oxides of iron, cobalt and nickel have probably disappeared in favor of the formation of more $\mathrm{Al}_{2} \mathrm{O}_{3}$ and $\mathrm{Cr}_{2} \mathrm{O}_{3}$. According to the Ellingham diagram, aluminum and chromium are able to reduce the oxides of nickel, cobalt and iron in the whole range of temperatures studied. Moreover, the reduction is effective when the metals are in contact with the oxides, which is facilitated by the nanoscale distribution of the phases in the agglomerates and the cracking of the passivating layers $\left(\mathrm{Al}_{2} \mathrm{O}_{3}\right)$ due to the creep of the underlying metal (Al).

The oxygen, carbon and nitrogen concentrations were measured together on a bulk sintered sample and the values are reported as follows: 0.8 at. $\% \mathrm{O}, 0.4$ at. $\% \mathrm{C}$ and 0.1 at. $\% \mathrm{~N}$. The oxygen content is quite high for this kind of structural alloy (especially compared to classic superalloy ingot) but not excessively high for alloys elaborated by powder metallurgy [41]. Contrary to what has previously been reported in the literature concerning HEA Spark Plasma Sintered samples [41-43], carbon contamination is of lesser magnitude than the oxygen contamination (as indeed the APT results suggested). In addition to the lack of PCA in the present study, this finding could be attributed to the greater amount of oxides, itself resulting from the presence of highly reactive elements. Indeed, during sintering, chromium carbide formation may be expected; however, more stable chromium oxides have likely already 
formed. In addition, the nano-oxides may slow down carbon diffusion by blocking diffusion paths such as grain boundaries. Hence, the initial oxygen contamination could serve to inhibit a potential carbon contamination occurring during sintering. Finally, if we consider that the whole of the oxygen measured is in the form of oxides, we note that there is approximately 0.5 wt. \% of oxides, far from enough to be observable by XRD (especially if the oxides are in two distinctive structures, $\mathrm{Cr}_{2} \mathrm{O}_{3}$ and $\mathrm{Al}_{2} \mathrm{O}_{3}$, as the $\mathrm{APT}$ result revealed).

The CALPHAD approach was used to gain insight into the kind of microstructure the alloy might have regarding its oxygen content. The phase volume fraction in $\mathrm{AlCoCrFeNiO}_{0.008}$ was calculated with the TCNI9 database (Thermo-Calc) and is presented in Fig. 6a. The composition was chosen according to the oxygen analyzer results, namely 0.8 at. \% of oxygen. At $1100{ }^{\circ} \mathrm{C}$, the sintering temperature, the microstructure is expected to be 58 vol. $\%$ $\mathrm{Al}_{28} \mathrm{Co}_{20} \mathrm{Cr}_{8} \mathrm{Fe}_{17} \mathrm{Ni}_{27}$ BCC-B2, 30 vol. $\% \mathrm{Al}_{6} \mathrm{Co}_{19} \mathrm{Cr}_{43} \mathrm{Fe}_{25} \mathrm{Ni}_{8}$ disordered $\mathrm{BCC}, 10$ vol. \% $\mathrm{Al}_{6} \mathrm{Co}_{23} \mathrm{Cr}_{30} \mathrm{Fe}_{26} \mathrm{Ni}_{15} \mathrm{FCC}$ and 2 vol. $\% \mathrm{Al}_{2} \mathrm{O}_{3}$. According to our calculations, the sigma phase, which has the exact same composition as the disordered $\mathrm{BCC}$, disappears at $1003^{\circ} \mathrm{C}$ to be replaced by this latter. Our calculations do not predict a chromium oxide phase except in extreme cases of $\mathrm{Cr}$ rich and $\mathrm{Al}$ poor composition.

Several discrepancies between thermodynamic simulations and our sample still exist, even when the oxygen content is taken into account. These discrepancies have been identified: the formation of the sigma phase even at $1100^{\circ} \mathrm{C}$, the formation of a greater amount of FCC and the stoichiometry of each phase. These discrepancies between experimental results and thermodynamic calculations also point to new hypotheses which could shed some light on experimental observations.

First, according to the calculations, the sigma phase is not stable above $1003^{\circ} \mathrm{C}$ yet this phase was observed in the three volumes analyzed by APT. The sigma phase could form during the cooling; however, the cooling rate is high (around $400{ }^{\circ} \mathrm{C} \cdot \mathrm{min}^{-1}$ ) in the sigma stability domain $\left(544-1003^{\circ} \mathrm{C}\right)$. This hypothesis hence seems unlikely. In addition, according to Bracq et al. [44], this phase seems difficult to predict with the current databases.

Secondly, the experimental volume ratio of the FCC phase is around $50 \%$ as compared to $10 \%$ in the calculations. This discrepancy may be partially explained by the extensive presence of $\mathrm{Al}$ and $\mathrm{Cr}$ oxides. We have calculated the phase evolution according to oxygen content at $1100^{\circ} \mathrm{C}$ (Fig. 6b). It appears that increasing oxygen content indeed leads to the formation of a greater amount of FCC and this hypothesis seems adequate. Indeed, as shown 
in Fig. 6c, aluminum mainly leaves the $\mathrm{Ni}-\mathrm{Al}$ rich $\mathrm{B} 2$ phase without modifying the $\mathrm{B} 2$ phase composition to form $\mathrm{Al}_{2} \mathrm{O}_{3}$ (see Fig. 6d). The significant heterogeneity of the milled powder revealed by oxygen quantification could also cause the formation of a greater amount of FCC. It is interesting to note that the TCNI9 database predicts a greater amount FCC than the TCHEA3 database (see [28] for instance). The main difference between the two databases is that the TCHEA3 database was mainly developed for equimolar and near equimolar solid solutions.

Finally, the experimental composition of the $\mathrm{B} 2$ phase is richer in $\mathrm{Al}$ and $\mathrm{Ni}$ than the calculated one. Significant trends are observed: Ni-Al on the B2 side and $\mathrm{Cr}-\mathrm{Fe}$ on the FCC side. The actual presence of the sigma phase at $1100^{\circ} \mathrm{C}$, depleting the $\mathrm{B} 2$ phase of $\mathrm{Cr}$, could accentuate the increase in $\mathrm{Al}$ content in the $\mathrm{B} 2$ phase.
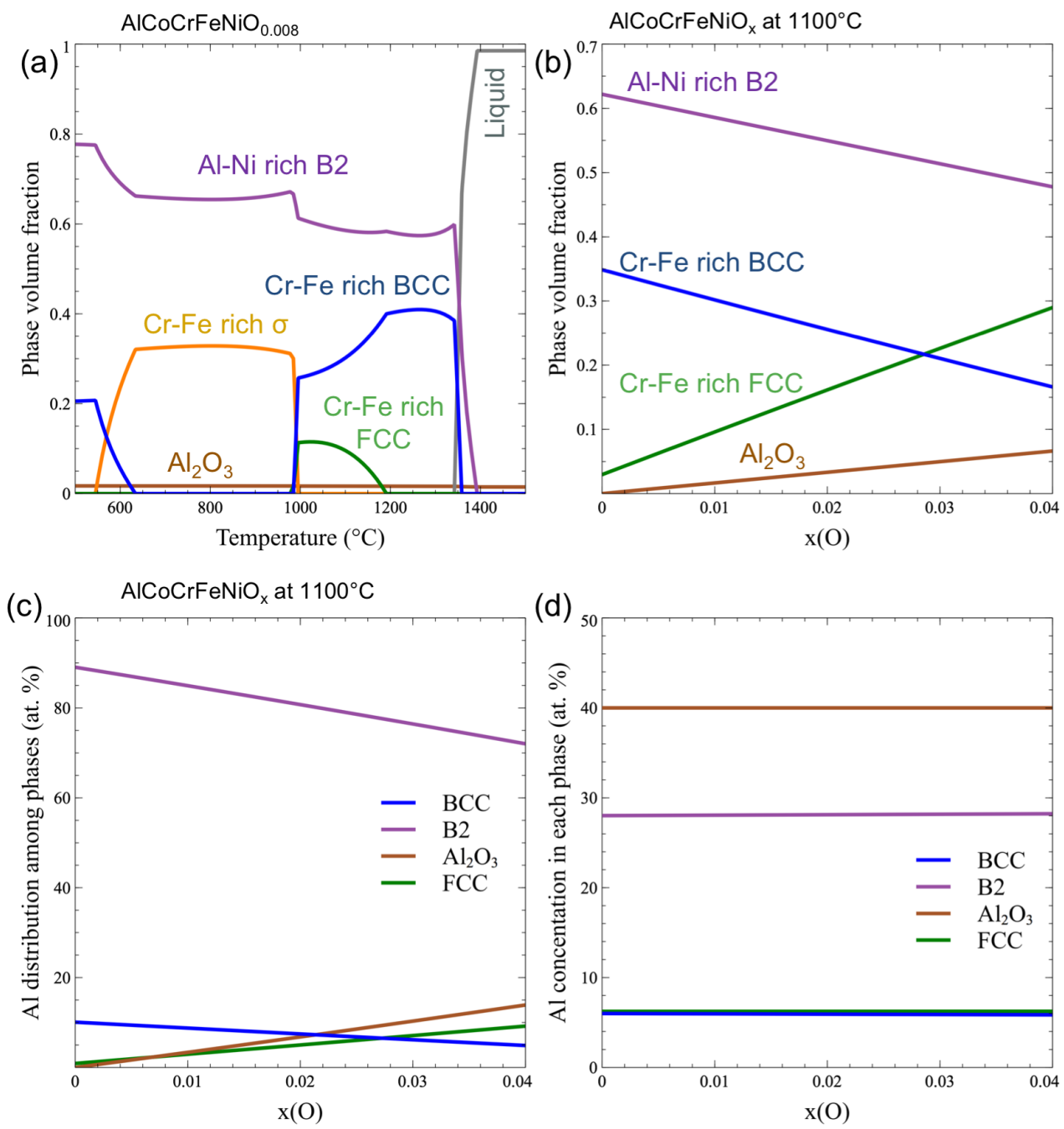

Figure 6: (a) Phase volume fraction as a function of temperature. (b) Phase volume fraction as a function of $O$ content. (c) Al distribution among phases as a function of $\mathrm{O}$ content. (d) Al concentration in each phase as a function of $O$ content. Thermo-Calc with TCNI9. 
Concerning the influence of these oxides on the mechanical properties of this sample, Orowan strengthening is a well-known way to improve mechanical properties. Oxide Dispersed Strengthened Steels (ODS) are the combination of a ductile metallic matrix and hard oxide inclusions, often Yttria, and are a perfect example of this idea. In the field of HEAs produced by powder metallurgy, several works have reported studies of ODS HEAs elaborated by Powder Metallurgy [45-48]. For instance, Prasad et al. added alumina to a FeNiCoCrAlMn matrix and noted that this addition had no effect on the phase formation during sintering. They also demonstrated that the hardness and thermal stability of the alloy were enhanced by these inclusions [49]. Gwalani et al. analyzed the microstructure of sintered $\mathrm{Al}_{0.3} \mathrm{CoCrFeMnNi}$ reinforced by $\mathrm{Y}_{2} \mathrm{O}_{3}$ by means of APT. The nanoscale characterization revealed that $\mathrm{Y}-\mathrm{Al}-\mathrm{O}$ complex oxides formed during the sintering [50,51]. Recently, several works have reported the advantages of producing alloys reinforced by the formation of native oxides, i.e., oxides formed from the oxygen present during the process or in the starting materials. In the field of additive manufacturing, Qiu showed that selective laser melting of a Fe-Ni alloy with a high oxygen level led to the formation of nano-oxide and to a combination of high strength and ductility [52]. A similar method was applied by Chen et al. to the CoCrFeNiMn high entropy alloy and was revealed to be promising [53]. In the powder metallurgy field, Moravcik et al. elaborated $\mathrm{Co}_{1.5} \mathrm{CrFeNi}_{1.5} \mathrm{Ti}_{0.5}$ by means of Mechanical Alloying and SPS. The formation of nano-sized TiO particles was achieved without any supplementary oxygen addition. The nano-sized oxides and coherent $\mathrm{Ni}_{3}$ Ti precipitates in the FCC matrix led to a good combination of strength and ductility [54]. In most of these works, hard particles are used to strengthen a matrix known for its ductility. In the present work, $\mathrm{Al}$ and $\mathrm{Cr}$ oxides are found in a peculiar microstructure of closely interlinked BCC and FCC phases. It is reasonable to suggest that this ODS dual phase alloy is still somewhat ductile, but this hypothesis would require further confirmation. Conversely, the key features of mechanical activation on the synthesis of high entropy alloys and the origin of oxygen have here been closely analyzed. These findings could be valuable in the case of alloys with simpler microstructures such as $\mathrm{Al}_{0.3} \mathrm{CoCrFeNi}$, known to exhibit one single FCC phase. 


\section{Conclusion}

In this work, we have evaluated the combination of mechanical activation and reactive sintering as an alternative to Mechanical Alloying and sintering for the AlCoCrFeNi High Entropy Alloy. Medium energy ball milling of the five elemental powders led to highly reactive agglomerates. After Spark Plasma Sintering, the distinctive lamellar structure primarily consists of two closely imbricated FCC and BCC phases with nano-oxides.

Atom Probe Tomography of the sample confirmed the satisfactory chemical homogeneity of these two main phases. There is no significant elemental segregation due to the peculiar state of the milled agglomerates. The sample elaborated by reactive sintering exhibits excellent chemical homogeneity, even at the nanoscale. However, APT and elemental analyzer also highlighted a high oxide content. In addition, the carbon content was found to be of lesser magnitude as compared to similar alloys milled with PCA. Dry milling seems to be an efficient way to reduce carbon contamination without promoting the formation of oxides. Indeed, combined oxygen quantification and XPS results demonstrated that most of the oxygen came from the commercial powders.

The CALPHAD calculations showed that, by depleting the main phases of $\mathrm{Al}$ and $\mathrm{Cr}$, the presence of oxides could alter the phase composition and stability. As almost no work precisely reports the amount of unwanted, minor elements such as $\mathrm{C}, \mathrm{O}$ or $\mathrm{N}$, this could explain the large number of different microstructures reported in the HEA literature concerning AlCoCrFeNi. 
[1] J.-W. Yeh, S.-K. Chen, S.-J. Lin, J.-Y. Gan, T.-S. Chin, T.-T. Shun, C.-H. Tsau, S.-Y. Chang, Nanostructured High-Entropy Alloys with Multiple Principal Elements: Novel Alloy Design Concepts and Outcomes, Adv. Eng. Mater. 6 (2004) 299-303. https://doi.org/10.1002/adem.200300567.

[2] B. Cantor, I.T.H. Chang, P. Knight, A.J.B. Vincent, Microstructural development in equiatomic multicomponent alloys, Mater. Sci. Eng. A. 375-377 (2004) 213-218. https://doi.org/10.1016/j.msea.2003.10.257.

[3] D.B. Miracle, O.N. Senkov, A critical review of high entropy alloys and related concepts, Acta Mater. 122 (2017) 448-511. https://doi.org/10.1016/j.actamat.2016.08.081.

[4] T.M. Butler, M.L. Weaver, Oxidation behavior of arc melted AlCoCrFeNi multicomponent high-entropy alloys, J. Alloys Compd. 674 (2016) 229-244. https://doi.org/10.1016/j.jallcom.2016.02.257.

[5] M. Ren, B. Li, H. Fu, Formation condition of solid solution type high-entropy alloy, Trans. Nonferrous Met. Soc. China. 23 (2013) 991-995. https://doi.org/10.1016/S10036326(13)62557-1.

[6] W.-R. Wang, W.-L. Wang, S.-C. Wang, Y.-C. Tsai, C.-H. Lai, J.-W. Yeh, Effects of Al addition on the microstructure and mechanical property of AlxCoCrFeNi high-entropy alloys, Intermetallics. 26 (2012) 44-51. https://doi.org/10.1016/j.intermet.2012.03.005.

[7] M.M. Garlapati, M. Vaidya, A. Karati, S. Mishra, R. Bhattacharya, B.S. Murty, Influence of $\mathrm{Al}$ content on thermal stability of nanocrystalline $\mathrm{AlxCoCrFeNi}$ high entropy alloys at low and intermediate temperatures, Adv. Powder Technol. 31 (2020) 1985-1993. https://doi.org/10.1016/j.apt.2020.02.032.

[8] W. Ji, Z. Fu, W. Wang, H. Wang, J. Zhang, Y. Wang, F. Zhang, Mechanical alloying synthesis and spark plasma sintering consolidation of CoCrFeNiAl high-entropy alloy, J. Alloys Compd. 589 (2014) 61-66. https://doi.org/10.1016/j.jallcom.2013.11.146.

[9] S. Mohanty, T.N. Maity, S. Mukhopadhyay, S. Sarkar, N.P. Gurao, S. Bhowmick, K. Biswas, Powder metallurgical processing of equiatomic AlCoCrFeNi high entropy alloy: Microstructure and mechanical properties, Mater. Sci. Eng. A. 679 (2017) 299-313. https://doi.org/10.1016/j.msea.2016.09.062.

[10] A.S. Rogachev, N.A. Kochetov, A.V. Panteleeva, K.V. Kuskov, D.Y. Kovalev, A.S. Shchukin, S.G. Vadchenko, Y.B. Scheck, High-Energy Ball Milling and Spark Plasma Sintering of the CoCrFeNiAl High-Entropy Alloy, Metals. 10 (2020) 1489. https://doi.org/10.3390/met10111489.

[11] V. Shivam, Alloying behaviour, thermal stability and phase evolution in quinary AlCoCrFeNi high entropy alloy, Adv. Powder Technol. (2018) 10.

[12] J. Cieslak, J. Tobola, K. Berent, M. Marciszko, Phase composition of Al x FeNiCrCo high entropy alloys prepared by sintering and arc-melting methods, J. Alloys Compd. 740 (2018) 264-272. https://doi.org/10.1016/j.jallcom.2017.12.333.

[13] S. Varalakshmi, M. Kamaraj, B.S. Murty, Processing and properties of nanocrystalline CuNiCoZnAlTi high entropy alloys by mechanical alloying, Mater. Sci. Eng. A. 527 (2010) 1027-1030. https://doi.org/10.1016/j.msea.2009.09.019.

[14] M. Murali, S.P. Kumaresh Babu, J. Majhi, A. Vallimanalan, R. Mahendran, Processing and characterisation of nano crystalline $\mathrm{AlCoCrCuFeTi}{ }_{x}$ high-entropy alloy, Powder Metall. 61 (2018) 139-148. https://doi.org/10.1080/00325899.2018.1438230.

[15] J.M. Torralba, P. Alvaredo, A. García-Junceda, High-entropy alloys fabricated via powder metallurgy. A critical review, Powder Metall. 62 (2019) 84-114. https://doi.org/10.1080/00325899.2019.1584454.

[16] J.M. Torralba, P. Alvaredo, A. García-Junceda, Powder metallurgy and high-entropy alloys: update on new opportunities, Powder Metall. 63 (2020) 227-236. 
https://doi.org/10.1080/00325899.2020.1807713.

[17] I. Moravcik, J. Cizek, P. Gavendova, S. Sheikh, S. Guo, I. Dlouhy, Effect of heat treatment on microstructure and mechanical properties of spark plasma sintered AlCoCrFeNiTi0.5 high entropy alloy, Mater. Lett. 174 (2016) 53-56. https://doi.org/10.1016/j.matlet.2016.03.077.

[18] A. Nouri, C. Wen, Surfactants in Mechanical Alloying/Milling: A Catch-22 Situation, Crit. Rev. Solid State Mater. Sci. 39 (2014) 81-108. https://doi.org/10.1080/10408436.2013.808985.

[19] S. Praveen, A. Anupam, R. Tilak, R.S. Kottada, Phase evolution and thermal stability of $\mathrm{AlCoCrFe}$ high entropy alloy with carbon as unsolicited addition from milling media, Mater. Chem. Phys. 210 (2018) 57-61. https://doi.org/10.1016/j.matchemphys.2017.10.040.

[20] S.G. Sarwat, Contamination in wet-ball milling, Powder Metall. 60 (2017) 267-272. https://doi.org/10.1080/00325899.2017.1280647.

[21] M. Vaidya, A. Prasad, A. Parakh, B.S. Murty, Influence of sequence of elemental addition on phase evolution in nanocrystalline AlCoCrFeNi: Novel approach to alloy synthesis using mechanical alloying, Mater. Des. 126 (2017) 37-46. https://doi.org/10.1016/j.matdes.2017.04.027.

[22] C. Suryanarayana, Mechanical alloying and milling, Prog. Mater. Sci. 46 (2001) 1-184. https://doi.org/10.1016/S0079-6425(99)00010-9.

[23] M. Vaidya, G.M. Muralikrishna, B.S. Murty, High-entropy alloys by mechanical alloying: A review, J. Mater. Res. 34 (2019) 664-686. https://doi.org/10.1557/jmr.2019.37.

[24] E. Gaffet, F. Bernard, J.-C. Niepce, F. Charlot, C. Gras, G. Le Caër, J.-L. Guichard, P. Delcroix, A. Mocellin, O. Tillement, Some recent developments in mechanical activation and mechanosynthesis, J. Mater. Chem. 9 (1999) 305-314. https://doi.org/10.1039/a804645j.

[25] E. Colombini, R. Rosa, L. Trombi, M. Zadra, A. Casagrande, P. Veronesi, High entropy alloys obtained by field assisted powder metallurgy route: SPS and microwave heating, Mater. Chem. Phys. 210 (2018) 78-86. https://doi.org/10.1016/j.matchemphys.2017.06.065.

[26] R. John, A. Karati, M.M. Garlapati, M. Vaidya, R. Bhattacharya, D. Fabijanic, B.S. Murty, Influence of mechanically activated annealing on phase evolution in A10.3CoCrFeNi high-entropy alloy, J. Mater. Sci. 54 (2019) 14588-14598. https://doi.org/10.1007/s10853-019-03917-7.

[27] B. Kang, J. Lee, H.J. Ryu, S.H. Hong, Microstructure, mechanical property and HallPetch relationship of a light-weight refractory A10.1CrNbVMo high entropy alloy fabricated by powder metallurgical process, J. Alloys Compd. 767 (2018) 1012-1021. https://doi.org/10.1016/j.jallcom.2018.07.145.

[28] A. Fourmont, S. Le Gallet, O. Politano, C. Desgranges, F. Baras, Effects of planetary ball milling on $\mathrm{AlCoCrFeNi}$ high entropy alloys prepared by Spark Plasma Sintering: Experiments and molecular dynamics study, J. Alloys Compd. (2019) 153448. https://doi.org/10.1016/j.jallcom.2019.153448.

[29] E. Kewes, F. Dahlem, S. Bec, N. Estime, K. Hoummada, J. Grollemund, J.-L. Loubet, Multi-scale chemical characterization of a ground metallurgical-grade silicon powder, Powder Technol. 270 (2015) 98-103. https://doi.org/10.1016/j.powtec.2014.08.025.

[30] M.-H. Tsai, K.-Y. Tsai, C.-W. Tsai, C. Lee, C.-C. Juan, J.-W. Yeh, Criterion for Sigma Phase Formation in Cr- and V-Containing High-Entropy Alloys, Mater. Res. Lett. 1 (2013) 207-212. https://doi.org/10.1080/21663831.2013.831382.

[31] S.-H. Joo, H. Kato, M.J. Jang, J. Moon, E.B. Kim, S.-J. Hong, H.S. Kim, Structure and 
properties of ultrafine-grained $\mathrm{CoCrFeMnNi}$ high-entropy alloys produced by mechanical alloying and spark plasma sintering, J. Alloys Compd. 698 (2017) 591-604. https://doi.org/10.1016/j.jallcom.2016.12.010.

[32] A. Manzoni, H. Daoud, R. Völkl, U. Glatzel, N. Wanderka, Phase separation in equiatomic AlCoCrFeNi high-entropy alloy, Ultramicroscopy. 132 (2013) 212-215. https://doi.org/10.1016/j.ultramic.2012.12.015.

[33] R.M. Pohan, Microstructures and mechanical properties of mechanically alloyed and spark plasma sintered A10.3CoCrFeMnNi high entropy alloy, Mater. Chem. Phys. (2018) 9.

[34] L. He, E. Ma, Nanophase metallic alloys consolidated from powders prepared by mechanical alloying, Mater. Sci. Eng. A. 204 (1995) 240-245. https://doi.org/10.1016/0921-5093(95)09968-9.

[35] S. Hasani, M. Panjepour, M. Shamanian, The Oxidation Mechanism of Pure Aluminum Powder Particles, Oxid. Met. 78 (2012) 179-195. https://doi.org/10.1007/s11085-0129299-1.

[36] J. Sun, M.L. Pantoya, S.L. Simon, Dependence of size and size distribution on reactivity of aluminum nanoparticles in reactions with oxygen and MoO3, Thermochim. Acta. 444 (2006) 117-127. https://doi.org/10.1016/j.tca.2006.03.001.

[37] M. Cohen, THE FORMATION AND PROPERTIES OF PASSIVE FILMS ON IRON, Can. J. Chem. 37 (1959) 286-291. https://doi.org/10.1139/v59-037.

[38] D.W. Rice, P.B.P. Phipps, R. Tremoureux, Atmospheric Corrosion of Cobalt, J. Electrochem. Soc. 126 (1979) 1459-1466. https://doi.org/10.1149/1.2129307.

[39] L. Wang, D. Mercier, S. Zanna, A. Seyeux, M. Laurent-Brocq, L. Perrière, I. Guillot, P. Marcus, Study of the surface oxides and corrosion behaviour of an equiatomic CoCrFeMnNi high entropy alloy by XPS and ToF-SIMS, Corros. Sci. 167 (2020) 108507. https://doi.org/10.1016/j.corsci.2020.108507.

[40] E. Hryha, R. Shvab, M. Bram, M. Bitzer, L. Nyborg, Surface chemical state of Ti powders and its alloys: Effect of storage conditions and alloy composition, Appl. Surf. Sci. 388 (2016) 294-303. https://doi.org/10.1016/j.apsusc.2016.01.046.

[41] I. Moravcik, A. Kubicek, L. Moravcikova-Gouvea, O. Adam, V. Kana, V. Pouchly, A. Zadera, I. Dlouhy, The Origins of High-Entropy Alloy Contamination Induced by Mechanical Alloying and Sintering, Metals. 10 (2020) 1186. https://doi.org/10.3390/met10091186.

[42] R.M. Pohan, B. Gwalani, J. Lee, T. Alam, J.Y. Hwang, H.J. Ryu, R. Banerjee, S.H. Hong, Microstructures and mechanical properties of mechanically alloyed and spark plasma sintered A10.3CoCrFeMnNi high entropy alloy, Mater. Chem. Phys. 210 (2018) 62-70. https://doi.org/10.1016/j.matchemphys.2017.09.013.

[43] M. Li, Y. Guo, H. Wang, J. Shan, Y. Chang, Microstructures and mechanical properties of oxide dispersion strengthened $\mathrm{CoCrFeNi}$ high-entropy alloy produced by mechanical alloying and spark plasma sintering, Intermetallics. 123 (2020) 106819. https://doi.org/10.1016/j.intermet.2020.106819.

[44] G. Bracq, M. Laurent-Brocq, L. Perrière, R. Pirès, J.-M. Joubert, I. Guillot, The fcc solid solution stability in the Co-Cr-Fe-Mn-Ni multi-component system, Acta Mater. 128 (2017) 327-336. https://doi.org/10.1016/j.actamat.2017.02.017.

[45] H. Hadraba, Z. Chlup, A. Dlouhy, F. Dobes, P. Roupcova, M. Vilemova, J. Matejicek, Oxide dispersion strengthened CoCrFeNiMn high-entropy alloy, Mater. Sci. Eng. A. 689 (2017) 252-256. https://doi.org/10.1016/j.msea.2017.02.068.

[46] C.-L. Chen, Suprianto, Effects of nano-dispersoids on synthesis and characterization of low $\mathrm{Cr}$-containing CoNiFeMnCr high entropy alloy by mechanical alloying, Intermetallics. 113 (2019) 106570. https://doi.org/10.1016/j.intermet.2019.106570. 
[47] S. Yang, Y. Zhang, X. Yan, H. Zhou, J. Pi, D. Zhu, Deformation twins and interface characteristics of nano-A12O3 reinforced $\mathrm{Al} 0.4 \mathrm{FeCrCo} 1.5 \mathrm{NiTi} 0.3$ high entropy alloy composites, Mater. Chem. Phys. 210 (2018) 240-244. https://doi.org/10.1016/j.matchemphys.2017.11.037.

[48] Y. Song, S. Nam, Y. Kwon, K. Cho, K.-A. Lee, H. Choi, Effect of multiple oxides on the mechanical properties of $\mathrm{CoCrFeMnNi}$ high-entropy alloy matrix composites, Powder Metall. 0 (2021) 1-7. https://doi.org/10.1080/00325899.2021.1892988.

[49] H. Prasad, S. Singh, B.B. Panigrahi, Mechanical activated synthesis of alumina dispersed FeNiCoCrAlMn high entropy alloy, J. Alloys Compd. 692 (2017) 720-726. https://doi.org/10.1016/j.jallcom.2016.09.080.

[50] B. Gwalani, R.M. Pohan, J. Lee, B. Lee, R. Banerjee, H.J. Ryu, S.H. Hong, Highentropy alloy strengthened by in situ formation of entropy-stabilized nano-dispersoids, Sci. Rep. 8 (2018) 14085. https://doi.org/10.1038/s41598-018-32552-6.

[51] B. Gwalani, R.M. Pohan, O.A. Waseem, T. Alam, S.H. Hong, H.J. Ryu, R. Banerjee, Strengthening of A10.3CoCrFeMnNi-based ODS high entropy alloys with incremental changes in the concentration of Y2O3, Scr. Mater. 162 (2019) 477-481. https://doi.org/10.1016/j.scriptamat.2018.12.021.

[52] C. Qiu, A new approach to synthesise high strength nano-oxide dispersion strengthened alloys, J. Alloys Compd. 790 (2019) 1023-1033. https://doi.org/10.1016/j.jallcom.2019.03.221.

[53] P. Chen, C. Yang, S. Li, M.M. Attallah, M. Yan, In-situ alloyed, oxide-dispersionstrengthened $\mathrm{CoCrFeMnNi}$ high entropy alloy fabricated via laser powder bed fusion, Mater. Des. 194 (2020) 108966. https://doi.org/10.1016/j.matdes.2020.108966.

[54] I. Moravcik, L. Gouvea, V. Hornik, Z. Kovacova, M. Kitzmantel, E. Neubauer, I. Dlouhy, Synergic strengthening by oxide and coherent precipitate dispersions in highentropy alloy prepared by powder metallurgy, Scr. Mater. 157 (2018) 24-29. https://doi.org/10.1016/j.scriptamat.2018.07.034. 